DOI: $10.35643 /$ Info.25.1.1

Dossier temático: Miradas epistemológicas, históricas y conceptuales de las disciplinas de la información

\title{
Por uma história intelectual da arquivologia, da biblioteconomia e da museologia desde uma perspectiva transversal
}

For an intellectual history of archival science, library science and museum studies from a transversal perspective

\section{Carlos Alberto Ávila Araújo ${ }^{1}$}

\footnotetext{
${ }^{1}$ Professor Associado da Universidade Federal de Minas Gerais, Brasil, Av. Antonio Carlos 6627, Pampulha, 31270901, Belo Horizonte-MG, Correo electrónico: casal@eci.ufmg.br, ORCID: 00000003-0993-1912.
}

\section{Resumo}

Neste artigo é apresentada a história da evolução científica da arquivologia, da biblioteconomia e da museologia. São enfatizados os movimentos intelectuais que influenciaram ou perpassaram as três áreas, colocando questões e problemas comuns. Ao final, são analisadas as perspectivas contemporâneas. Conclui-se que as três áreas partiram de uma perspectiva de estudo mais simplificada e focada em elementos mais concretos caminhando, ao longo do tempo, para vertentes mais atentas à complexidade e a abstrações relacionadas aos fenômenos arquivísticos, biblioteconômicos e museológicos. Nesse movimento, as fronteiras disciplinares foram se tornando menos rígidas, favorecendo o surgimento de campos de pesquisa ou ações institucionais comuns.

Palavras-chave: ARQUIVOLOGIA; BIBLIOTECONOMIA; MUSEOLOGIA.

\footnotetext{
Abstract: In this article is presented the history of the scientific evolution of archival science, library science and museum studies. The intellectual movements that influenced or crossed the three areas are emphasized, asking common questions and problems. At the end, contemporary perspectives are analyzed. It is concluded that the three areas started from a more simplified study perspective and focused on more concrete elements, moving, over time, towards aspects more
} 
attentive to the complexity and abstractions related to archival, library and museum phenomena. In this movement, disciplinary boundaries were becoming less rigid, favoring the emergence of research fields or common institutional actions.

\section{Keywords: ARCHIVAL SCIENCE; LIBRARY SCIENCE; MUSEUM STUDIES.}

Data de entrega: 19/12/2019

Data de aceitação: 20/04/2020

\section{Introdução}

O objetivo deste artigo é analisar a história da arquivologia, da biblioteconomia e da museologia a partir de dois aspectos: primeiro, em termos de suas correntes teóricas ou escolas de pensamento; segundo, enfatizando intencionalmente aqueles aspectos que as aproximam.

Assim, em primeiro lugar é preciso abandonar a ideia de que essas áreas de estudo e pesquisa sejam uniformes, sejam consensualmente definidas e/ou reconhecidas. Ao contrário, o que se pode perceber é uma progressiva sequência de modos de se definir seu objeto, seus métodos e mesmo seus objetivos. Esses modos precisam ser analisados não apenas em suas ideias e conceitos, mas também em sua vinculação com contextos históricos. Tais contextos são compostos tanto pelo clima intelectual de uma época, mas também por fatores políticos, econômicos, sociais e culturais.

A tese aqui defendida é que as práticas arquivísticas, biblioteconômicas e museológicas, que têm uma existência desde milênios atrás, conduziram a efetivas áreas de conhecimento no período imediatamente posterior ao Renascimento europeu, áreas estas voltadas especificamente para as instituições arquivo, biblioteca e museu. Ao longo dos séculos seguintes, até o século XIX, foram se consolidando seus contornos de campo específico do conhecimento até sua legitimação científica.

Ao longo do século $\mathrm{XX}$, contudo, já como disciplinas científicas, as três áreas conheceram processos de ampliação de seu escopo de estudo e dos métodos de pesquisa, que aconteceram de maneira paralela e com distintas filiações às 
correntes de pensamento das ciências humanas e sociais. Tal movimento conduziu, no século XXI, a um conjunto de novas perspectivas de estudo focadas não nas instituições arquivo, biblioteca e museu, mas sim na compreensão de tais instituições enquanto um momento do social, da realidade humana - com foco nas ações de arquivalização, mediação bibliotecária ou informação, musealização, em suma, nas maneiras como uma sociedade lida com o conhecimento e a cultura, como decide preservar alguns conhecimentos e descartar outros, como decide valorizar alguns, preservar outros, elaborar instrumentos para difundir ou tornar acessíveis determinados conteúdos.

Mais uma vez, deve-se destacar que a arquivologia, a biblioteconomia e a museologia não se desenvolvem no vácuo, sujeitas apenas a suas dinâmicas internas - elas também são afetadas por questões de natureza epistemológica, social, cultural e política, que atuam diretamente sobre o desenho dos seus objetivos, modos de pensar, aplicações e, sobretudo, o objeto de pesquisa, já que é a teoria que determina o que podemos observar.

Ao final, argumenta-se sobre as potencialidades proporcionadas pela criação de um espaço de efetivo diálogo entre as áreas, superando a rigidez das barreiras disciplinares sem ameaçar a autonomia científica de cada uma delas.

\section{Do surgimento dos estudos sobre arquivos, bibliotecas e museus até o século XIX}

Antes de existirem a arquivologia, a biblioteconomia e a museologia como campos de conhecimento, existiram as práticas arquivísticas, biblioteconômicas e museológicas, que acompanham a humanidade desde que o ser humano tornou-se um ser de cultura, isto é, capaz de simbologizar (White, 2009) de interpretar o mundo e de produzir registros materiais dessas ações em qualquer tipo de suporte físico (Kuper, 2002). Com a invenção da escrita e do estabelecimento das primeiras cidades, surgiram os primeiros espaços específicos voltados para a guarda e a preservação de acervos documentais. No Egito Antigo, na Grécia Clássica, no Império Romano, nos mundos árabe e chinês do primeiro milênio e na Idade Média na Europa, existiram vários arquivos, bibliotecas e museus, relacionados com os mais diversos fins - religiosos, políticos, econômicos, artísticos, jurídicos, etc. 
Nestas instituições, ao longo dos séculos, foram se desenvolvendo diversos conhecimentos técnicos e práticos. Um conhecimento propriamente teórico e sistematizado apareceu no período imediatamente posterior ao Renascimento, com a publicação dos primeiros tratados relativos a estas instituições (Inscriptiones vel tituli theatri amplissimi de Samuel Quiccheberg, de 1535; Advis pour dresser une bibliothèque, de Gabriel Naudé, de 1627; e De re diplomática, de Jean Mabbilon, de 1681). Nesta época, renasceu o interesse pela produção humana, pelas obras artísticas, filosóficas e científicas - tanto as da Antiguidade Greco-Romana como aquelas que se desenvolviam no próprio momento. Salientou-se assim o interesse pelo culto das obras, pela sua guarda, sua preservação.

Entre os séculos XV e XVII foram publicados diversos tratados e manuais voltados para as regras de procedimentos nas instituições responsáveis pela guarda das obras, para as regras de preservação e conservação física dos materiais, para as estratégias de descrição formal das peças e documentos, incluindo aspectos sobre sua legitimidade, procedência e características. A produção cultural humana, compreendida como um "tesouro" que precisaria ser devidamente preservado, tornou-se objeto de uma visão patrimonialista (o conjunto da produção intelectual e estética humana, a ser guardado e repassado para as gerações futuras). O interesse centrou-se no conteúdo dos acervos, sendo que arquivos, bibliotecas e museus eram vistas como instituições a serviço dos campos de estudo da literatura, das artes, da história e das ciências. Não se construíram, neste momento, conhecimentos arquivísticos, biblioteconômicos ou museológicos consistentes (para além de algumas regras operativas muito próximas do senso comum), mas apenas conhecimentos artísticos, literários, filosóficos ou históricos sobre os conteúdos guardados nestas instituições.

Após a Revolução Francesa e as demais revoluções burguesas na Europa, verificou-se uma profunda transformação em todas as dimensões da vida humana (na política, na economia, no direito) e, dessa forma, também os arquivos, as bibliotecas e os museus foram transformados. Surgiram os conceitos modernos de "Arquivo Nacional", "Biblioteca Nacional", "Museu Nacional", que têm no caráter público sua marca distintiva e como instituições paradigmáticas os Archives Nationales de França (1790), o Museé du Louvre (1793) e a Library of 
Congress nos Estados Unidos (1800). Formaram-se as grandes coleções, com amplos processos de aquisição e acumulação de acervos - o que reforçou a natureza custodial destas instituições. A necessidade de se ter pessoal qualificado para as nascentes instituições modernas levou à formação dos primeiros cursos profissionalizantes, voltados essencialmente para regras de administração das rotinas destas instituições e, seguindo a tradição anterior, para conhecimentos gerais em humanidades.

Um terceiro momento da construção dos conhecimentos arquivísticos, biblioteconômicos e museológicos ocorreu no século XIX, exatamente no período da consolidação da ciência moderna como forma legítima de produção de conhecimento e de intervenção na natureza e na sociedade. Nesse momento foram publicados diversos manuais que buscaram estabelecer o projeto de constituição científica da arquivologia, da biblioteconomia e da museologia. O modelo de ciência então dominante, oriundo das ciências exatas e naturais, voltado para a busca de regularidades, estabelecimento de leis, ideal matemático e intervenção na natureza por meio de processos técnicos e tecnológicos, se expande para as ciências sociais e humanas através do positivismo. Esse é o modelo que inspirou as pioneiras conformações científicas das três áreas, que privilegiou os procedimentos técnicos de intervenção: as estratégias de inventariação, catalogação, descrição, classificação e ordenação dos acervos documentais de arquivos, bibliotecas e museus. Arquivologia, biblioteconomia e museologia tornaram-se as ciências voltadas para o desenvolvimento das técnicas de tratamento dos acervos que custodiam. Ao mesmo tempo, o movimento de consolidação positivista destas áreas de conhecimento promoveu sua autonomização de outras áreas das quais eram apenas campos auxiliares (como as artes, a história, a literatura). São exemplares desse momento as obras Handleiding voor het ordenen en beschrijven van archieven, de autoria de S. Muller, J. A. Feith e R. Fruin, publicado em 1898; A classification and subject index, for cataloguing and arranging the books and pamphlets of a library, de Melvil Dewey, publicada em 1876; Aufbau der niederländischen Kunstgeschichte und Museologie, de Georg Rathgeber, de 1839; e Praxis der Naturgeschichte, de Phillip Leopold Martin, publicada em 1869. 
Os três movimentos acima destacados se somam. A perspectiva patrimonialista voltou-se para os "tesouros" que deveriam ser custodiados, ressaltando a importância da produção simbólica humana. Ainda que preservado em parte o sincretismo verificado nos séculos anteriores, há já alguma distinção entre arquivos, bibliotecas e museus. A entrada na modernidade enfatizou as especificidades das instituições arquivos, bibliotecas e museus, que deveriam ter estruturas organizadas e rotinas estabelecidas para o exercício da custódia. E a fundamentação positivista priorizou as técnicas particulares de cada instituição a serem utilizadas para o correto tratamento do material custodiado. Constituem-se assim, nos finais do século XIX e início do século XX, os elementos que marcam a consolidação de um determinado modelo para as três áreas.

Uma das consequências deste modelo foi a consolidação da separação entre as três áreas. Tal separação foi com as ações, nas primeiras décadas do século XX, das associações profissionais em prol do estabelecimento das distinções entre os profissionais de arquivo, de biblioteca e de museu. Ao longo do século XX, contudo, o desenvolvimento de reflexões e teorias nas três áreas não conduziu ao fortalecimento do modelo dominante no século XIX. Ao contrário, a vasta produção científica que se seguiu identificou, com muita freqüência, os vários limites desse modelo, ressaltando diversos aspectos que, aos poucos, foram conduzindo à necessidade de sua superação. Além disso, novos fatores e elementos surgidos neste século (como a crescente importância da informação e do conhecimento nos setores produtivos da sociedade, o desenvolvimento das tecnologias digitais, o incremento das práticas interdisciplinares no ambiente científico e a crescente importância da especificidade das ciências sociais e humanas) também exerceram importante papel na mudança do cenário de atuação de arquivos, bibliotecas e museus, conduzindo a iniciativas práticas que também evidenciavam mudanças no paradigma dominante. Para a apresentação destes conhecimentos e teorias optou-se, neste artigo, por sua vinculação a correntes teóricas que se deram de maneira semelhante ou transversal às três áreas.

\section{O rumo dos estudos no século $\mathrm{XX}$}

Ao longo do século XX, a produção científica em arquivologia, biblioteconomia e museologia foi influenciada pelas correntes teóricas que se desenvolveram e 
atravessaram praticamente todas as ciências humanas e sociais. No caso destas três áreas, é possível identificar com clareza quatro grandes movimentos teóricos. O primeiro deles é o funcionalismo, que representou a primeira mudança significativa no teor da produção intelectual sobre arquivos, bibliotecas e museus, no século XX, com a introdução, em ensaios e manifestos, de expressões como "o arquivo precisa ser efetivamente útil", "a biblioteca deve ser viva" e "o museu deve ser dinâmico", entre outras. Nesse momento, estudiosos criticavam fortemente o fato de estas instituições estarem voltadas apenas para seus acervos e suas técnicas, sugerindo que elas buscassem atuar ativamente nos contextos sociais em que se inseriam. E, ao propor isso, provocaram também mudanças consideráveis nas formulações teóricas.

Em comum, essas várias manifestações têm como fundamento o funcionalismo: uma perspectiva que se sustenta numa visão da realidade humana a partir da inspiração biológica do organismo vivo, em que a sociedade humana é entendida como um todo orgânico, composto de partes que desempenham funções específicas necessárias para a manutenção do equilíbrio do todo. Estudos funcionalistas se voltaram, pois, para a determinação das funções (no caso, dos arquivos, das bibliotecas e dos museus), para verificar se as funções estão ou não sendo cumpridas (e para a identificação e eliminação dos obstáculos que impedem seu cumprimento), para a identificação de disfunções que possam estar ocorrendo e a formulação de estratégias para superá-las.

O segundo movimento deu-se com a construção de perspectivas de estudos críticos em praticamente todas as ciências humanas e sociais, como uma reação à hegemonia do pensamento positivista. Contra as perspectivas das ciências humanas e sociais que buscavam estabelecer padrões e regularidades, as manifestações críticas defendiam o caráter histórico da realidade, reivindicando o estudo dos contextos históricos para a compreensão dos fenômenos. Em oposição ao funcionalismo, que almejava o bom funcionamento do social, as teorias críticas argumentavam que o conflito, e não a integração, constitui o principal fundamento explicativo da realidade humana. Com a arquivologia, a biblioteconomia e a museologia deu-se o mesmo. Arquivos, bibliotecas e museus passaram a ser estudados não mais com o objetivo de se identificar as funções que deveriam desempenhar para o bom funcionamento do todo social mas, sim, a partir de seu 
papel nas dinâmicas de poder e dominação, principalmente a partir da identificação de suas dimensões ideológicas.

O terceiro movimento relaciona-se com o desenvolvimento, nas diferentes ciências humanas e sociais, de perspectivas de estudo que enfatizavam o caráter ativo dos indivíduos na construção das instituições, normas e fenômenos sociais. Tais perspectivas filiaram-se a tradições de pensamento distintas como a hermenêutica, a fenomenologia e o construtivismo. No caso da arquivologia, da biblioteconomia e da museologia, a influência desses estudos se deu com o desenvolvimento de campos de pesquisa voltados para os usuários, visitantes ou público destas instituições, que passaram a ser vistos como objeto de estudo científico.

A quarta linha de pensamento que teve forte incidência nas ciências humanas e sociais, ao longo do século $\mathrm{XX}$, se relaciona com as perspectivas de estudo centradas na linguagem e no simbólico, que se manifestaram em áreas tão distintas como a semiótica, a semiologia, os estudos em representação, a filosofia da linguagem e muitas outras. Nos campos da arquivologia, da biblioteconomia e da museologia, essa vertente intelectual acabou por problematizar a questão da representação das coleções guardadas nos arquivos, nas bibliotecas e nos museus. Essa representação deixou de ser vista apenas como uma questão técnica (inventariá-las para fins de controle e guarda, catalogá-las e classificá-las para fins de recuperação, descrevê-las para facilitar o acesso e o uso), passando a contemplar as várias dimensões envolvidas na representação e na produção e reprodução dos processos de significação. De tarefa técnica, pois, as questões da representação se converteram em importante campo de investigação científica.

Nos tópicos seguintes, serão identificados os estudos e pesquisas, em cada uma das três áreas, vinculados a esses quatro movimentos intelectuais.

\section{A arquivologia no século $\mathrm{XX}$}

$\mathrm{Na}$ arquivologia, as primeiras manifestações do pensamento funcionalista se encontram nos manuais pioneiros de Jenkinson, de 1922, e de Casanova, de 1928, que apontavam para a necessidade de os arquivos terem um impacto efetivo no aumento da eficácia organizacional. Sua formulação mais consistente se deu com o desenvolvimento da subárea de avaliação de documentos e, nela, principalmente 
com a "escola norte-americana" da primeira metade do século XX, com os trabalhos de Warren (a partir dos quais formalizou-se uma associação que seria $o$ embrião da American Records Management Association); de Brooks, sobre as três categorias de valor, e principalmente de Schellenberg, sobre o valor primário e secundário dos documentos arquivísticos (Delsalle, 2000). Em conjunto, tais proposições visavam conservar o máximo de informação preservando um mínimo de documentos - priorizando a funcionalidade em oposição aos aspectos de arranjo e valor histórico dos documentos. Uma outra vertente arquivística, também funcionalista, é a que priorizou a ação cultural dos arquivos, suas funções culturais e pedagógicas, que também provocou a busca por uma maior “dinamização” destas instituições (Alberch i Fugueras et al, 2001).

A perspectiva crítica apareceu pela primeira vez com Bautier, que estudou os interesses ideológicos que motivaram critérios usados pelos arquivos ainda no início da era moderna. Outros estudos se deram sobre a questão do poder de posse dos documentos em várias ocasiões, como no caso dos processos de descolonização da África e da Ásia (SILVA et al, 1998). Nas décadas de 1960 e 1970, debates sobre as políticas nacionais de informação promovidos pela Unesco tematizaram o papel dos arquivos, a questão do direito à informação e a necessidade de transparência por parte do Estado (Jardim, 1995). Numa linha distinta, autores como Colombo argumentaram contra a obsessão das sociedades contemporâneas com o arquivamento e o registro das atividades humanas. Mais recentemente, desenvolveu-se uma perspectiva de estudos inaugurada com Terry Cook que buscou superar os pressupostos de neutralidade e passividade das práticas arquivísticas, analisando em que medida os arquivos constituem espaços em que relações de poder são negociadas, contestadas e confirmadas - numa virada de ênfase das coleções para os contextos. Autores como Caswell, Harris e Montgomery estudaram realidades arquivísticas específicas, por exemplo em regimes totalitários, a partir de conceitos de Arendt e Derrida, a partir do caminho iniciado por Cook.

Já os estudos a partir da perspectiva dos sujeitos, expressa na problematização da relação entre os usuários e os arquivos, começou a ser discutida na década de 1960, dentro das reflexões sobre o acesso aos arquivos nas reuniões do Conselho Internacional de Arquivos (SILVA et al, 1998), sendo os estudos pioneiros os de 
Taylor, Dowle, Dearstyne, Pugh, Cox e Wilson, voltados para o entendimento das necessidades informacionais de diferentes tipos de usuários (Jardim, Fonseca, 2004). Há também estudos de usuários no campo dos trabalhos de dinamização cultural, principalmente sobre tipologia de usuários e, mais recentemente, sobre cidadãos e seus interesses em história familiar e em atividades de ensino (Coueré, Duclert, 2001).

Por fim, a temática relativa à representação teve como marco a criação dos princípios de organização e descrição de documentos arquivísticos, que surgiu e foi debatida desde o início da disciplina. A partir de 1898, com a publicação do manual dos holandeses Muller, Feith e Fruin, ela ganhou um estatuto diferente, abrindo-se caminho para a construção de um espaço reflexivo sobre as normas e técnicas arquivísticas. Diversas aplicações práticas de instrumentos de classificação, inclusive de sistemas de classificação bibliográfica, foram testados nos anos seguintes, embora sem uma significativa reflexão teórica - o que só aconteceu em manuais posteriores, como os de Tascón, de 1960, e de Tanodi, em 1961, e em obras teóricas de pesquisadores como Schellenberg. Nas décadas de 1970 autores como Laroche e Duchein problematizaram os princípios de ordenamento confrontando o conceito de record group surgido nos EUA com o princípio da proveniência europeu. No final desta década, autores como Dollar e Lytle inseriram a questão dos registros eletrônicos e a recuperação da informação (Silva et al, 1998). Os aspectos relacionados com preservação e autenticidade também estiveram no centro dos debates sobre os documentos digitais, envolvendo pesquisadores como Duranti e Lodolini, que buscaram confirmar o valor do princípio de proveniência e o respeito aos fundos como critério fundamental da arquivologia. O impacto dos suportes digitais também motivou o crescimento da pesquisa na área de normalização arquivística, principalmente a partir da ideia de interoperabilidade de sistemas e possibilidade de ligação em rede, envolvendo pesquisadores, associações profissionais e entidades governamentais. A temática da indexação dos documentos arquivísticos (representação por assuntos) também vem ganhando espaço nos últimos anos (Ribeiro, 2003).

\section{A biblioteconomia no século $X X$}


Na biblioteconomia, os movimentos pelas bibliotecas públicas na Inglaterra e nos Estados Unidos, surgidos no século XIX, com críticas a seu caráter auto-centrado e elitista, marcam o início da perspectiva funcionalista (Murison, 1988). Outra novidade foi a introdução do serviço de referência, a partir de 1876, com os esforços de Green que defendia inovações práticas nas bibliotecas para aumentar a acessibilidade física e intelectual (Fonseca, 1992). A consolidação científica dessa vertente se deu na Universidade de Chicago, onde em 1928 foi criado o primeiro doutorado em Biblioteconomia. Autores como Butler, Shera, Danton e Williamson defendiam uma biblioteconomia científica, voltada não para os processos técnicos mas para o cumprimento de suas funções sociais - ou seja, o fundamento da biblioteca se encontra no fato de ela ir ao encontro de certas necessidades sociais. Teóricos de diferentes países, tais como Lasso de la Vega, Litton, Buonocore, Mukhwejee e Usherwood, seguiram essas orientações, ao defender o conceito de biblioteca como instituição democrática, ativa, e não como depósito de livros (López Cózar, 2002). Na Índia, Ranganathan desenvolveu as cinco "leis" da biblioteconomia, defendendo o efetivo uso da biblioteca e de seus recursos e, ao mesmo tempo, o atendimento às necessidades da sociedade, por meio do atendimento a cada um de seus componentes. Desenvolvimentos posteriores de leis ou princípios da biblioteconomia, como os de Thompson e de Urquhart, também priorizaram as funções sociais e a necessidade de as bibliotecas serem dinâmicas e ativas. Recentemente, estudos sobre as tipologias de bibliotecas e sobre os impactos das tecnologias audiovisuais e digitais de informação também se inserem nesta perspectiva, buscando otimizar o papel da biblioteca e dinamizar o uso de seus recursos.

As manifestações de um pensamento crítico surgiram em países de terceiro mundo, vinculadas aos processos de redemocratização após ditaduras militares. Num primeiro momento, tais manifestações foram de caráter prático (com a criação de novos serviços bibliotecários de extensão), com o objetivo de proporcionar acesso ao conhecimento por parte de populações socialmente excluídas. Anos depois, foram formuladas teorias relacionadas a essas práticas no escopo das reflexões sobre ação cultural e animação cultural, nas quais o bibliotecário deveria atuar numa perspectiva de emancipação em relação à dominação ideológica (Flusser, 1983). As bibliotecas deveriam ser dinâmicas e 
ativas, mas contra os processos de alienação - num sentido bem diferente da perspectiva funcionalista (Milanesi, 2002).

Já os estudos desde a perspectiva dos sujeitos tiveram suas primeiras manifestações com os estudos de comunidade realizados por pesquisadores da Universidade de Chicago, que tinham como foco os grupos sociais tomados em seu conjunto. Foram realizadas diversas pesquisas empíricas, nas três décadas seguintes, sobre hábitos de leitura e fontes de informação mais usadas. Aos poucos, o interesse foi se deslocando para a avaliação dos serviços bibliotecários, convertendo os estudos de usuários em estudos de uso para diagnóstico de bibliotecas. Situando-se na temática de Avaliação de Coleções, tais estudos impulsionaram várias inovações técnicas, tais como a disseminação seletiva de informações. Na década de 1970, pesquisadores como Line, Paisley, Brittain e Totterdall deslocaram o foco de interesse para as necessidades de informação dos usuários (Cunha, Amaral, Dantas, 2015). Recentemente, destacam-se as pesquisas de autores como Kuhlthau e Todd no ambiente da biblioteca escolar, numa perspectiva cognitivista, identificando o uso da informação nas diferentes fases do processo de pesquisa escolar.

A problemática da representação desenvolveu-se, na biblioteconomia, primeiro com o campo da catalogação, relacionada com a descrição dos aspectos formais dos documentos, que teve suas primeiras regras e princípios formulados ainda no século XIX. A partir da década de 1960, padrões internacionais de descrição bibliográfica foram formulados e envolveram diversos grupos de estudo. Também nesta época surgiram os primeiros modelos de descrição pensando-se na leitura por computador, gerando padrões que, anos depois, conformariam o campo conhecido como metadados. Outro campo é o da classificação, que teve início com a criação dos primeiros sistemas de classificação bibliográfica gerais e enumerativos, como os de Dewey, Otlet, Bliss e Brown. Na primeira metade do século XX, os trabalhos de Ranganathan sobre classificação facetada revolucionaram o campo, propondo formas flexíveis e não-hierarquizadas de classificação, (Souza, 2007). Nos anos seguintes, diversos campos e setores de pesquisa estabeleceram diálogo ou se apropriaram dos princípios da classificação facetada, tais como os tesauros facetados de Aitchison, a Teoria do conceito de Dahlberg, os estudos de bases de dados facetados de Neelameghan, a abordagem 
dos boundary objects de Albrechtsen e Jacob, as pesquisas em estruturas de classificação de Kwasnik, e o mapeamento de sentenças para a evidenciação de facetas por Beghtol. 


\section{A museologia no século $\mathrm{XX}$}

$\mathrm{Na}$ museologia, a área de educação museológica foi a primeira manifestação de uma abordagem funcionalista e se desenvolveu sobretudo no ambiente anglosaxão, propondo-se ser uma museologia verbal, voltada para a ação, erigida em oposição à tradição anterior cujo símbolo maior era o Louvre - a tradição nominalista, voltada para a posse e a descrição dos objetos (Gómez Martínez, 2006). No início do século XX desenvolveu-se, sobretudo nos Estados Unidos, uma museologia voltada para a eficácia dos museus, para uma efetiva difusão de certos valores junto à população, e para oferecer à sociedade um "retorno" dos investimentos feitos. Autores como Flower, Goode e Dana marcavam a especificidade dos novos museus como instituições que teriam como valor não a contemplação, mas o uso, e que não esperariam pelos visitantes, mas iriam buscálos, atraindo-os para os museus por meio da eliminação de barreiras e da busca por acessibilidade. Diversas parcerias foram realizadas com o setor privado para o incremento de atividades industriais e comerciais, resultando em inovações museográficas (Zeller, 1989). Essa perspectiva manifestou-se em diversos outros contextos, como na França com Malraux e no Canadá com Cameron. A partir da década de 1980, com as tecnologias digitais, houve uma revitalização da corrente funcionalista, com as possibilidades de acesso remoto, interatividade e design de exposições. Outras subáreas mais específicas da museologia, também funcionalistas, são a dos estudos em tipologias de museus (já que, a diferentes tipos, correspondem diferentes funções) e a de gestão de museus a partir de estratégias de marketing, envolvendo autores como Moore e Tobelem.

As manifestações pioneiras de pensamento crítico se encontram na obra de artistas e ensaístas como Zola, Valéry e Marinetti, nas primeiras décadas do século XX, que viam o museu como um mausoléu, como uma instituição que degradava a arte, instrumento de poder de alguns povos sobre outros. Na década de 1960, uma nova onda de críticas provocou o aparecimento de formas de antimuseu, com importantes inovações museológicas (Bolaños, 2002). Depois, por meio de uma aproximação com a sociologia da cultura e os trabalhos de Bourdieu, estudou-se como diferentes grupos sociais tinham relações distintas com os museus, e como eles eram utilizados como instrumento de distinção social. Outros estudos buscam 
correlacionar o papel dos museus na construção ideológica da ideia de nação, a partir do trabalho pioneiro de Anderson. Há ainda uma área recente, a museologia crítica, voltada para a crítica das estratégias museológicas intervenientes nos patrimônios naturais e humanos e seu possível caráter destruidor (Santacana Mestre, Hernández Cardona, 2006).

O estudo sobre os sujeitos se deu, na Museologia, como parte da grande mudança na concepção sobre os museus: de depósitos de objetos para lugares de aprendizagem, operou-se uma alteração do foco, das coleções para os públicos surgindo desse movimento a subárea de estudos de visitantes (Hooper-Greenhill, 1998). No começo do século XX foram realizados os primeiros estudos empíricos, com Galton seguindo os visitantes pelos corredores dos museus e Gilman estudando a fadiga e os problemas de ordem física na concepção de exposições. As primeiras investigações com maior rigor ocorreram no final da década de 1920, sendo o primeiro estudo de comportamento dos visitantes publicado por Robinson em 1928. Na década de 1940, proliferaram estudos sobre os impactos nas exposições junto aos visitantes, realizados por autores como Cummings, Derryberry e Melton. Outros estudos, conduzidos por autores como Rea e Powell na mesma época, tiveram como objetivo traçar perfis sócio-demográficos dos visitantes e mapear seus hábitos culturais (Pérez Santos, 2000). Na década de 1960, Shettel e Screven inauguraram uma nova perspectiva com as medidas de aprendizagem nos estudos de visitantes. Nas décadas seguintes, desenvolveram-se abordagens de base cognitivista, sobre a efetividade das exposições (Eason, Friedman, Borun), e de natureza construtivista - como o modelo tridimensional de Loomis, a teoria dos filtros de McManus, o modelo sociocognitivo de Uzzell, a abordagem comunicacional de Hooper-Greenhill e o modelo contextual de Falk e Dierking. Em comum, essas várias abordagens buscaram ver como os usuários interpretam as exposições museográficas, construindo significados diversos, imprevisíveis, relacionados com suas distintas vivências, experiências e contextos socioculturais (Davallon, 2005).

Por fim, o espírito nacionalista e historiográfico dos primeiros museus modernos foi decisivo para a configuração dos primeiros critérios de ordenamento, descrição, classificação e exposição dos acervos nos museus (Mendes, 2009). A subárea de documentação museológica surgiu no início do século XX, a partir do 
trabalho de autores como Wittlin, Taylor e Schnapper (Marín Torres, 2002). Nas décadas de 1920 e 1930 houve grandes debates sobre os critérios de classificação adotados nos museus, mas a temática só se converteu em campo de investigação décadas depois. Entre as várias abordagens desenvolvidas, encontram-se aquelas que buscaram problematizar aspectos classificatórios dos museus, como a questão da representação dos gêneros, dos diferentes povos do mundo, das diferentes culturas humanas, numa linha marcada pelos estudos culturais (Pearce, 1994).

\section{Estudos sobre arquivos, bibliotecas e museus no século XXI}

Os avanços mais recentes nos campos da arquivologia, biblioteconomia e museologia têm buscado agregar as várias contribuições das últimas décadas. Novos tipos de instituições, serviços e ações executadas no âmbito extrainstitucional conferiram maior dinamismo aos campos, que passaram a se preocupar mais com os fluxos e a circulação dos conhecimentos e da informação. Buscando superar os modelos voltados apenas para a ação das instituições junto ao público, ou para os usos e apropriações que o público faz dos acervos, surgiram modelos voltados para a interação e a mediação, contemplando as ações reciprocamente referenciadas destes atores. Modelos sistêmicos também apareceram na tentativa de integrar ações, acervos ou serviços antes contemplados isoladamente. A própria ideia de acervo, ou coleção, foi problematizada, na esteira de questionamentos sobre o objeto de estudo das três áreas. Somado a tudo isso, desenvolveram-se as tecnologias digitais com um impacto muito mais profundo, reconfigurando tanto o fazer quanto a teorização destes três campos.

Na arquivologia, na década de 1960, houve uma maior teorização sobre o objeto do campo e uma ampliação de seus domínios (como os arquivos administrativos, os arquivos privados e de empresas); e ainda o surgimento de campos novos (os arquivos sonoros, visuais e o uso do microfilme). Outra inovação é a arquivística integrada, que surgiu no começo dos anos 1980 com a busca de uma síntese dos records management e da archives administration, a partir de uma visão global dos arquivos, considerando a gestão de documentos no campo de ação da arquivologia, isto é, abarcando as tradicionalmente chamadas três idades dos documentos numa perspectiva integrada. Outras temáticas contemporâneas são as que relacionam os arquivos com as atividades de registro da história oral, e o 
campo dos arquivos pessoais e familiares (Cox, 2008). Estudos recentes também têm destacado a necessidade de se estudar os arquivos como construções sociais, propondo-se que a arquivologia deveria acabar com a tradicional fissura entre a lógica do arquivo e a sociedade no qual ele se insere (Thomassen, 2006; Delgado Gómez, Cruz Mundet, 2010). Nessa mesma perspectiva, cada vez mais vêm sendo desenvolvidos estudos vinculando as questões arquivísticas às questões de construção de identidade por meio da memória no plano conceitual (Cook, 2013; Jacobsen, Punzalan, Hedstrom, 2013), ou em estudos relativos a identidades étnicas (Daniel, 2013) e de determinados grupos sociais (Caron, Kellerhals, 2013). Dentro das abordagens contemporâneas em biblioteconomia, destacam-se três grandes tendências que, embora possam ser separadamente identificadas, possuem vários elementos em comum. A primeira delas é a da mediação da informação, que se expressa numa alteração estrutural do conceito de biblioteca, sendo esta considerada menos como uma coleção de livros e outros documentos, devidamente classificados e catalogados, e mais como assembleia de usuários da informação (Fonseca, 1992). Assim, a ideia de mediação enfatiza menos o caráter difusor (de transmissão de conhecimentos) e mais o caráter dialógico da biblioteca (Almeida Jr., 2009). A segunda vertente se construiu a partir do conceito de competência informacional, surgido em 1974, voltado para a identificação e a promoção de habilidades informacionais dos sujeitos, que não são mais entendidos apenas como usuários portadores de necessidades informacionais (Campello, 2003). Por fim, a terceira vertente é a dos estudos sobre as bibliotecas eletrônicas ou digitais, com todas as implicações em termos de acervos, serviços e dinâmicas relativas a essa nova condição (Rowley, 2002). Exemplos de aplicações desta perspectiva são, por exemplo, estudos de uso de hashtags do twitter (Chang, Iyer, 2012) ou de sistemas sociais de descoberta (Spiteri, Tarulli, 2012) para a construção de catálogos de bibliotecas. Nessa mesma linha, Lankes (2011) propõe uma nova biblioteconomia, na qual o papel dos bibliotecários seria ajudar no progresso das sociedades facilitando a produção de conhecimentos nas várias comunidades. Essa mudança na questão da mediação da biblioteca também vendo sendo compreendida a partir do conceito de esfera pública (Ventura, 2002) ou de makerspaces (Alonso Arévalo, 2018), como local a proporcionar condições de envolvimento e participação por meio do acesso à informação. 
Na museologia, merece destaque o desenvolvimento dos ecomuseus e da chamada nova museologia. Conforme Davis (1999), o conceito de ecomuseu surgiu no começo do século XX, sob o impacto das ideias ambientalistas, de conceitos relativos à ecologia e ecossistemas, com a criação dos museus ao ar livre, que, numa perspectiva ampliada de museu, incorporavam sítios geológicos ou naturais ao seu acervo. Um outro sentido para o termo foi dado, a partir das ideias de Rivière, Hugues de Varine e Bazin, que propôs repensar o significado da própria instituição museu. Nessa visão, os museus deveriam envolver as comunidades locais no processo de tratar e cuidar de seu patrimônio. Tal noção propõe que a museologia passe a estudar a relação das pessoas com o patrimônio cultural e que o museu seja entendido como instrumento e agente de transformação social - o que significa ir além das suas funções tradicionais de identificação, conservação e educação, em direção à inserção da sua ação nos meios humano e físico, integrando as populações. Soma-se a isso a recente ênfase nos estudos sobre a musealização do patrimônio imaterial. Alargando seus horizontes dessa forma, a museologia se desloca da ênfase nos objetos para a dimensão imaterial, da ação humana e dos sentidos construídos. A diversidade cultural, além disso, vem se constituindo como um dos principais valores museológicos, experimentada e proporcionada pela expografia (Purkis, 2013) e pela representação de minorias étnicas nos museus (Kim, 2011). Por fim, o fenômeno contemporâneo dos museus virtuais representa uma dimensão com variados desdobramentos práticos e teóricos. Para Deloche (2002), a chegada da tecnologia digital à realidade dos museus acarreta a reformulação da própria concepção de instituição museal. Nesse sentido, têm sido desenvolvidos estudos numa área específica denominada museum informatics, que trata das interações sociotécnicas (entre as pessoas, a informação e a tecnologia) nos espaços museais (Marty, Jones, 2008). Aliada à discussão do patrimônio imaterial, também tal dimensão relaciona-se ao que vem sendo conhecido como patrimônio cultural digital (Zorich, 2010), com o uso de tecnologias digitais na descrição dos objetos expostos a partir de metodologias centradas nas experiências dos públicos e na utilização de dispositivos móveis (Saffle, 2013) e para a promoção de acessibilidade por meio de tecnologias digitais (Lisney et al, 2013; Linzer, 2013). 


\section{Considerações finais}

A evolução teórica na arquivologia, na biblioteconomia e na museologia aponta para a efetiva superação do modelo consolidado no final do século XIX em torno das coleções (patrimônio), das instituições e das técnicas de tratamento técnico. Progressivamente foram sendo incorporadas nos estudos outras dimensões dos arquivos, das bibliotecas e dos museus: suas funções sociais, suas inserções nas contradições e ideologias, as apropriações e usos deles feitas pelos sujeitos, os processos de significação acionados pelas dinâmicas representacionais, até chegar ao momento em que estudar arquivos, bibliotecas e museus é, antes de tudo, estudar determinada realidade social e cultural, é focar no visível (nas instituições e práticas documentais) para se chegar ao invisível (as relações que uma sociedade estabelece com o conhecimento que ela produz, como o valoriza, o descarta, o faz circular, etc).

Assim, a dinâmica mais ampla dos processos passou a ser contemplada, com objetos que vão desde a produção dos registros (e até mesmo o que ainda não possui existência física, o imaterial), a composição dos acervos, as competências dos usuários no uso e apropriação dos acervos, até as diferentes camadas de significação criadas com a intervenção profissional e os instrumentos de descrição e classificação. Na museologia, tal passagem pode ser caracterizada com a mudança do objeto museu para a musealidade (Poulot, 2013) ou o museal (Stránský, 1980); na arquivologia com o conceito de "arquivalia" de Tanodi (2009), de arquizalização de Ketelaar (2018) ou o de arquivo total (Silva et al, 1998); e na biblioteconomia com o próprio conceito de informação (Rendón Rojas, 2005; Alfaro López, 2010).

Se o desenho das reflexões que vão do Renascimento ao século XIX ancora-se na extrema concretude dos objetos (a instituição, os acervos, as técnicas), as perspectivas desenvolvidas no século $\mathrm{XX}$ foram importantes para deslocar e ampliar o eixo de preocupações. E é o aprofundamento desse processo que acaba por conduzir às perspectivas contemporâneas, mais atentas à complexidade dos fenômenos e à interrelação de seus elementos constituintes.

Neste artigo buscou-se demonstrar, ainda, como parte considerável das reflexões científicas em arquivologia, em biblioteconomia e em museologia, desenvolvidas ao longo do século XX, se deu de maneira transversal, com o desenvolvimento de 
vários pontos e aspectos comuns, em vez de um reforço da construção de fronteiras e limites entre elas. Essa característica de aproximação vem se fortalecendo no âmbito das perspectivas contemporâneas, que têm privilegiado os fluxos, as interações, o extrainstitucional e o imaterial. Enfim, seria possível dizer que elas têm enfatizado aquilo que existe na realidade como potencialmente arquivístico, biblioteconômico ou museológico, tendo como objeto, assim, não mais as instituições, os objetos ou as técnicas de tratamento, mas a relação mesma do ser humano com a realidade mediada pelas atuações/intervenções produzidas (ou a serem produzidas) por essas áreas.

Essa realidade vem sendo, de certa forma, antecipada por uma série de iniciativas práticas, eventos e modelos formativos. Cumpre destacar, além disso, a existência de uma diversificada produção científica do início do século XXI relacionada especificamente com as aproximações entre arquivologia, biblioteconomia e museologia. Tais aproximações têm aparecido, na literatura, em relação às possibilidades de formação profissional convergente nas três áreas (Trant, 2009; Accart, 2014), de curadoria e desenvolvimento de coleções com aspectos comuns entre as três (Beasley, 2007; Maron, Yun, Pickle, 2013), de oferecimento de serviços comuns (Kalfatovic et al, 2008), de complementaridade entre elas na criação de comunidades de conhecimento (Hedstrom, King, 2004), na valorização do conhecimento nas sociedades contemporâneas (Kirchhoff, Schweibenz, Sieglersch, 2008), na defesa da democracia (Clough, 2013), de convergências entre as três nos ambientes digitais (Given, McTavich, 2010; Marty, 2009; Michalko, 2007; Whyte, 2007), de possibilidades de interoperabilidade entre seus sistemas (Gartner, Mouren, 2019), de convergência entre suas missões (Dupont, 2007) e, de uma forma geral, de defesa da colaboração entre profissionais e instituições das três áreas (Marcum, 2014; Waibel, Erway, 2009; Zorich, Waibel, Erway, 2008) incluindo intercâmbio de "boas práticas" a serem seguidas por elas (Yarrow, Clubb, Drapper, 2008).

Tudo isso colabora para uma parcial dissolução das rígidas fronteiras disciplinares (sem perda de identidade e de especificidade de cada uma) em benefício de reflexões teóricas e aplicações práticas mais ricas - como demonstram, entre outros, os recentes exemplos de construção da Europeana (um amplo sistema digital que constitui ao mesmo tempo um arquivo, uma biblioteca e um museu de 
acervos da cultura europeia) ou a fusão do Arquivo Nacional e da Biblioteca Nacional no Canadá. Todas essas ações institucionais e desenvolvimentos teóricos conduz ao diálogo necessário para a construção de um conhecimento científico que não se reduz ao estudo e à prática das instituições que cada área contempla, mas sim que possibilita que as três áreas sejam mais do que "a ciência do arquivo", "a ciência da biblioteca" e "a ciência do museu" - e ainda possam se fortalecer mutuamente e, mais ainda, atuar para uma sociedade que valorize cada vez mais a cultura, a ciência e o conhecimento numa perspectiva inclusiva, plural, participativa, crítica e guiada por uma cultura da paz.

\section{Referências}

Accart, J.-P. (2014). Regards croisés sur les métiers des sciences de l'information: bibliothèques, archives, documentation, musées. MontSaint-Aignan: Éditions Klog

Alberch i Fugueras, R. et al. (2001). Archivos y cultura: manual de dinamización. Gijón: Trea.

Alfaro López, H. (2010). Estudios epistemológicos de bibliotecología. México: UNAM.

Almeida Jr., O. (2009). Mediação da informação e múltiplas linguagens. Tendências da Pesquisa Brasileira em Ciência da Informação, 2 (1), 89103.

Alonso Arévalo, J. (2018) Makerspaces y bibliotecas. Barcelona: UOC.

Beasley, G. (2007). Curatorial crossover: building library, archives, and museum collections. RBM: a journal of rare books, manuscripts, and cultural heritage, 8 (1), 20-28.

Bolaños, M. (2002). La memoria del mundo: cien años de museología: 19002000. Gijón: Trea. 
Campello, B. (2003). O movimento da competência informacional: uma perspectiva para o letramento informacional. Ciência da Informação, 32 (3), 28-37.

Caron, D., Kellerhals, A. (2013). Archiving from self-ascertainment, identitybuilding and permanent self-questioning: archives between skepticism and certitude. Archival science, 13 (2-2), 207-216.

Chang, H.-C., Iyer, H. (2012). Trends in twitter hashtag applications: design features for value-added dimensions to future library catalogues. Library trends, 61 (1), 248-258.

Clough, W. (2013). Best of both worlds: museums, libraries and archives in a digital age. Washington: Smithsonian Institute.

Coeuré, S., Duclert, V. (2001). Les archives. Paris: La Découverte.

Cook, T. (1997). What is past is prologue: a history of archival ideas since 1898, and the future paradigm shift. Archivaria, 43, 17-63.

Cook, T. (2013) Evidence, memory, identity, and community: four shifting archival paradigms. Archival science, 13 (2-3), 95-120.

Cox, R. (2008). Personal archives and a new archival calling: readings, reflections and ruminations. Duluth: Litwin.

Cunha, M, Amaral, S., Dantas, E. (2015). Manual de estudo de usuários da informação. São Paulo: Atlas.

Daniel, D. (2013). Archival representations of immigration and ethnicity in North American history: from the ethnicization of archives to the archivization of ethnicity. Archival science, v. 14, 169-203.

Davallon, J. (2005). Penser la muséologie. En: J. Davallon, B. Schiele (Ed.). Doctorat en Museólogie, mediation, patrimoine (pp. 69-98). Sainte-Foy: Multimondes. 
Davis, P. (1999). Ecomuseums: a sense of place. London: Leicester University Press.

Delgado Gómez, A., Cruz Mundet, J. (2010). El archivo como construcción social. Candelaria: Asarca.

Deloche, B. (2002). El museo virtual. Gijón: Trea.

Delsalle, P. (2000). Une histoire de l'archivistique. Sainte-Foy: Presses de l'Université du Québec.

Dupont, C. (2007). Libraries, archives, and museums in the twenty-first century: 174 intersecting missions, converging futures? RBM: a Journal of Rare Books, Manuscripts, and Cultural Heritage, 8 (1), 13-19.

Flusser, V. (1983). A biblioteca como um instrumento de ação cultural. Revista da Escola de Biblioteconomia da UFMG, 12 (2), 145-169.

Fonseca, E. (1992). Introdução à biblioteconomia. São Paulo: Pioneira.

Gartner, R., Mouren, R. (2019). Archives, museums and libraries: breaking the metadata silos. Paper presented at: IFLA WLIC 2019 - Athens, Greece Libraries: dialogue for change in Session 206 - Art Libraries with Subject Analysis and Access. Recuperado de: http://library.ifla.org/2495/.

Given, L., Mctavish, L. (2010). What's old is new again: the reconvergence of libraries, archives, and museums in the digital age. Library Quarterly, 80 (1), 7-32.

Gómez Martínez, J. (2006). Dos museologías: las tradiciones anglosajona y mediterránea-diferencias y contactos. Gijón: Trea.

Hedstrom, M., King, J. (2004). On the lam: library, archive, and museum collections in the creation and maintenance of knowledge communities. Paris: Organisation for Economic Co-operation and Development, 2004. Recuperado de: http://www.oecd.org/education/innovationeducation/32126 054.pdf. 
Hooper-Greenhill, E. (1998). Los museos y sus visitantes. Gijón: Trea.

Jacobsen, T., Punzalan, R., Hedstrom, M. (2003). Invoking ‘colective memory’: mapping the emergence of a concept in archival science. Archival science, $13(2-3), 217251$.

Jardim, J. (1995). Sistemas e políticas públicas de arquivos no Brasil. Niterói: EdUff.

Jardim, J., Fonseca, M. O. (2004). Estudos de usuários em arquivos: em busca de um estado da arte. Datagramazero, 5 (5).

Kalfatovic, M. et al. (2008). Smithsonian team Flickr: a library, archives and museums collaboration in web 2.0 space. Archival Science, 8 (4), 267-277.

Ketellar, E. (2018). (Des)construir o arquivo. En: L. Heymann, L. Nedel (Ed.). Pensar os arquivos. Rio de Janeiro: FGV, pp. 193-206.

Kim, K. (2011). Multiculturalism and Chinese museums. Working Papers in Museum Studies, 7, 1-27. Recuperado de: http://deepblue.lib.umich.edu/bitstream/handle/2027.42/102519/7_kim_20 11_0.pdf?sequence=1.

Kirchhoff, T., Schweibenz, W., Sieglersch, J. (2008). Archives, libraries, museums and the spell of ubiquitous knowledge. Archival Science, 8 (4), 251-266.

Kuper, A. (2002). Cultura: a visão dos antropólogos. Bauru: Edusc.

Lankes, D. (2011). The atlas of new librarianship. Cambridge: MIT Press.

Linzer, D. (2013). Learning by doing: experiments in accessible technology at the Withney Museum of American Arts. Curator: the museum journal, 56 (3), 363-367.

Lisney, E. et al. (2013). Museums and technology: being inclusive helps accessibility for all. Curator: the museum journal, 56 (3), 353-361. 
López Cózar, E. (2002). La investigación en biblioteconomía y documentación. Gijón: Trea.

Marcum, D. (2014). Archives, Libraries, Museums: Coming Back Together? Information \& Culture, 49 (1), 74-89.

Marín Torres, M. T. (2002). Historia de la documentación museológica: la gestión de la memoria artística. Gijón: Trea.

Maron, N., Yun, J., Pickle, S. (2013). Sustaining our digital future: institutional strategies for digital content. Strategic Content Alliance, 2013. 88 p. Recuperado de: http://sca.jiscinvolve.org/wp/files/2013/01/Sustaining-ourdigital-future-final-31.pdf.

Marty, P. (2009). An introduction to digital convergence: libraries, archives, and museums in the information age. Museum Management and Curatorship, 24 (4), 295-298.

Marty, P., Jones, K. (2008). Museum informatics: people, information and technology in museums. New York: Routledge.

Mendes, J. (2009). Estudos do patrimônio: museus e educação. Coimbra: Univ. Coimbra.

Michalko, J. (2007). Libraries, archives, and museums: achieving scale and relevance in the digital age. RBM: a Journal of Rare Books, Manuscripts, and Cultural Heritage, 8 (1), 75-79.

Milanesi, L (2002). Biblioteca. São Paulo: Ateliê.

Murison, W. (1988). The public library: its origins, purpose and significance. London: C. Bingley.

Pearce, S. (Ed.). (1994). Museums and the appropriation of culture. London: Athlone.

Pérez Santos, E. (2000). Estudio de visitantes en museos: metodología y aplicaciones. Gijón: Trea. 
Poulot, D. (2013). Museu e museologia. Belo Horizonte: Autêntica.

Purkis, P. (2013). Making contact in an exhibition zone: displaying contemporary cultural diversity in Donegal, Ireland, through an installation of visual and material portraits. Museum and society, 11 (1), 50-67.

Rendón Rojas, M. (2005). Bases teóricas y filosóficas de la bibliotecología. México: UNAM.

Ribeiro, F. (2003). O acesso à informação nos arquivos. Lisboa: Fundação Calouste Gulbenkian; MCT; MCEC.

Rowley, J. (2002). A biblioteca eletrônica. Brasília: Briquet de Lemos.

Saffle, K. (2013). Reinventing museum labels: overcoming an archtype with technology and visitor-centered label writing. Journal of Museum Studies, $7(1), 1-15$.

Santacana Mestre, J., Hernández Cardona, F. (2006). Museologia crítica. Gijón: Trea.

Silva, A. et al. (1998). Arquivística: teoria e prática de uma ciência da informação. Porto: Afrontamento.

Souza, R. (2007). Organização do conhecimento. En: L. Toutain (Ed.). Para entender a ciência da informação (pp. 103-123). Salvador: EdUFBA.

Spiteri, L., Tarulli, L. (2012) Social discovery systems in public libraries: if we build them, will they come? Library trends, 61 (1), 132-147.

Stránský, Z. (1980). Museology as a Science (a Thesis). Museologia, 15 (11), 3339.

Tanodi, A. (2009). Manual de archivología hispano-americana: teorías y princípios. Córdoba: Brujas.

Thomassen, T. (2006). Uma primeira introdução à arquivologia. Arquivo \& Administração, 5 (1), 5-16. 
Trant, J. (2009) Emerging convergence? Thoughts on museums, archives, libraries and professional training. Museum Management and Curatorship, 24 (4), 369-387.

Venura, J. (2002). Bibliotecas e esfera pública. Oeiras: Celta.

Waibel, G., Erway, R. (2009). Think globally, act locally: library, archive and museum collaboration. Museum Management and Curatorship, 24 (4), 323-335.

White, L. (2009). O conceito de cultura. Rio de Janeiro: Contraponto.

Wythe, D. (2007). New technologies and the convergence of libraries, archives, and museums. RBM: a Journal of Rare Books, Manuscripts, and Cultural Heritage, 8 (1), 51-55.

Yarrow, A., Clubb, B., Draper, J.-L. (2008). Public libraries, archives and museums: trends in collaboration and cooperation. The Hague: IFLA.

Zeller, T. (1989). The historical and philosophical foundations of art museum education in América. En: N. Berry, S. Mayer (Ed.). Museum education: history, theory and practice (pp. 10-89). Reston: National Art Education Association

Zorich, D. (2010). A survey on digital cultural heritage initiatives and their sustainability concerns. En: R. Parry (Ed.). Museums in a digital age, 406416. Oxon: Routledge.

Zorich, D., Waibel, G., Erway, R. (2008). Beyond the silos of the LAMs: collaboration among libraries, archives and museums. Dublin: OCLC Online Computer Library Center. 